\title{
International Trade and Foreign Investment: A Model with Asymmetric Production
}

\author{
M. ALI KHAN*
}

We present a two-country model of trade and investment in which the output of one country is used as an intermediate input in the other country. Our work extends and qualifies recent work of Kemp and Ohyama and also has a bearing on the theory of foreign investment with sector-specific capital.

\section{INTRODUCTION}

Kemp and Ohyama [10] and Findlay [3] have revived interest in the study of an asymmetrical world economy in which a group of resource-poor but capitalrich countries trade with and invest in a corresponding group of resource-rich but capital-poor countries. Their work relies on a two-country model but one which fundamentally departs from standard trade theory in not assuming that the countries are identical in all respects except factor endowments. One of the striking results to come out of this line of research is that there is no limit to the extent to which the resource-poor country can exploit the resource-rich country by suitable instruments of commercial policy but that "the latter can exploit the former only partially". However, it is somewhat surprising that no one has asked how robust this and other results are with respect to the assumption of each country being completely specialized. We do this here by introducing an additional sector in the resource-poor country. This has the further advantage that by bringing labour allocation to the fore, it allows us to examine a wider set of issues - in particular those pertaining to the taxation of labour employed in the sector with foreign capital.

Our model can also be looked on as a variation on a recent piece of Jones and Dei [7] which develops the theory of trade and investment based on the RicardoViner assumption of sector-specific capital. Specifically, we examine the extent to

*Professor of Economics, Cornell University and Johns Hopkins University, USA. This paper was presented at the Annual General Meeting of the Pakistan Society of Development Economists held at Islamabad in March 1984. The author is grateful to I. Ahmed, Syed Nawab Haider Naqvi and J. Seade for comments and discussion and to Yong-Bang Chung for correspondence. A version of this paper was also presented at Professor Ron Jones's Trade Theory Workshop at the University of Rochester. The author very much wishes that he could have had the time to revise extensively the present version in the light of the suggestions received at Rochester and Islamabad. As it stands, the paper should be seen as a first presentation of the results. Responsibility for errors is, of course, solely that of the author. 
which the Jones-Dei results require modification if their assumption of both countries producing an identical commodity with an internationally mobile factor of production is replaced by one in which the output of the non-specialized country is used as an intermediate input in the production process of the other.

Finally, our work has a bearing on the theory of optimal policy associated with the names of Jones [5] and Kemp [8]. This theory derives formulae for the optimal interference in the markets for capital and final products from the viewpoint of national advantage. Our relevant results can be seen as an extension of this theory to a set-up which allows, and therefore calls for, interference also in the market for a purely intermediate good.

Section 2 presents the model and preliminary analysis. Section 3 is devoted to comparative statics and discusses how four instruments of commercial policy affect outputs, international capital movements and factor returns. Section 4 is devoted to questions of optimal policies from the viewpoint of national advantage. Both Sections 3 and 4 are based on the assumption that the prices of the final goods are exogenously given and Section 5 examines the consequence of relaxing this assumption. Section 6 ends the paper with two concluding remarks.

\section{THE MODEL AND PRELIMINARY ANALYSIS}

Let there be three commodities, $m, r$ and $f$, produced in two countries, Industria and Resourcia. Industria is specialized and produces manufactures $m$ in accordance with a well-behaved, ${ }^{1}$ constant-returns-to-scale production function and using as inputs, capital, labour and a primary resource. We may thus write

$$
X_{m}=F_{m}\left(L^{*}, K_{m}, X_{r}\right) \quad \ldots \quad \quad \ldots \quad \ldots . \quad \ldots
$$

Following Kemp and Ohyama [10], we shall also assume ${ }^{2} F_{m}^{23} \geqslant 0$ where subscripts denote differentials with respect to the corresponding variables. Resourcia produces the primary resource $r$ as well as food $f$, both in accordance with well-behaved ${ }^{3}$ constant-return-to-scale production functions but with sector-specific capital, say land and capital, and with labour as the only intersectorally mobile factor of production. We may thus write

$$
X_{r}=F_{r}\left(L_{r}, K_{r}\right) ; X_{f}=F_{f}\left(L_{f}, T\right) \quad \ldots \quad \ldots \quad \ldots
$$

${ }^{1}$ We shall assume that a "well-behaved" production function is twice continuously differentiable in each of its arguments with strictly diminishing marginal productivities.

${ }^{2}$ This constitutes (3c) on page 95 in their paper.

${ }^{3}$ See footnote 1 above.
We assume that there is international mobility of capital between Industria and the primary resource sector in Resourcia and that both countries are endowed with positive amounts of labour and capital, i.e. $\left(K^{*}, L^{*}\right)$ and $(K, L)$ respectively. We thus obtain the following material balance equations.

$$
\begin{array}{rlllll}
K_{m}+K_{r}=K+K^{*} \equiv K & & \ldots & \ldots & \ldots & \ldots \\
L_{r}+L_{f}=L & \ldots & \ldots & \ldots & \ldots & \ldots
\end{array}
$$

On the pricing side we assume competitive markets and subsume the marginal productivity conditions into the underlying unit cost functions. ${ }^{4}$ We may thus write

$$
p_{m}=C_{m}\left(w^{*}, R, p_{r}\right) ; p_{r}=C_{r}(w, R) ; p_{f}=C_{f}(w, q) \quad \ldots
$$

where $w, w^{*}$ are the respective wage rates, $R$ the rental rate of capital, $q$ the return to land and $p_{i}$ the price of commodity $i, i=m, r, f$. All that remains is a specification of demand. We assume that both countries share identical homothetic preference patterns and can therefore write

$$
\begin{array}{lllllll}
D\left(p_{m} / p_{f}\right)=X_{m} & \ldots & \ldots & \ldots & \ldots & \ldots
\end{array}
$$

Our model is now completely specified and it is worth observing that a specialized Resourcia yields the Kemp-Ohyama model and that the Jones-Dei model is obtained if Industrian manufacturing is independent of the primary resource.

Now let us assume the existence of a unique equilibrium in which Resourcia is not completely specialized. One way to think of this equilibrium is to let commodity $f$ be the numeraire and assume fixed values of $K_{r}$ and $p_{r}$. This allows us to focus on Resourcia and observe that we are in the Ricardo-Viner world of Jones, Samuelson and Neary ${ }^{5}$ for which the responses of $L_{r}, L_{f}, X_{r}, X_{f}, R, q$ and $w$ to $p_{r}$ and $K_{r}$ are well understood. On substituting these responses into the price equals cost equation for Industria and equations (2.3) and (2.6), we can determine the equilibrium values of $p_{r}$ and $K_{r}$. To see this, simply rewrite the equilibrium condition in the international capital market (2.3) as

$$
C_{m}^{2}\left(w^{*}, R, p_{r}\right) X_{m}+K_{r}=K \quad \ldots \quad \quad \ldots \quad \quad \ldots
$$

and that in the Industrian labour market as

${ }^{4}$ The properties of these cost functions are by now well understood; see, for example, Gorman's Tricks piece [4].

${ }^{5}$ See Jones $[6]$, Samuelson [13] and Neary [12]. 


$$
C_{m}^{1}\left(w^{*}, R, p_{r}\right) X_{m}=L^{*} \quad \ldots \quad \ldots \quad \ldots \quad \ldots
$$

where again subscripts denote differentials with respect to the corresponding variable. Both (2.7) and (2.8) are equations in the $p_{r}-K_{r}$ plane if the dependence of $w^{*}$ on $p_{r}, K_{r}$ is obtained from (2.6) and the first equation in the system (2.5).

The above procedure brings out clearly how our model is a simple extension of the Ricardo-Viner model to a two-country setting. However, it is ill-suited for comparative static analysis. For this, it is much more efficient and natural to think in terms of primal variables. In this case, we can reduce our equilibrium to the $L_{r}-K_{r}$ plane and the remainder of this section is devoted to this. Given competitive markets, we can alternatively write equation (2.5) as

$$
\begin{array}{lllllll}
p_{m} F_{m}^{2}=R=p_{r} F_{r}^{2} & \ldots & \ldots & \ldots & \ldots & \ldots \\
p_{m} F_{m}^{3}=p_{r} & \ldots & \ldots & \ldots & \ldots & \ldots & \ldots \\
p_{f} F_{f}^{1}=w=p_{r} F_{r}^{1} & \ldots & \ldots & \ldots & \ldots & \ldots
\end{array}
$$

From these, we can obtain our basic equations

$$
\begin{array}{lllllll}
F_{r}^{2}=F_{m}^{2} / F_{m}^{3} & \ldots & & \ldots & \ldots & \ldots & \ldots \\
p_{m} F_{m}^{3} F_{r}^{1}=p_{f} F_{f}^{1} & & \ldots & & \ldots & \ldots & \ldots
\end{array}
$$

It is clear that on using equation (2.6) we can reduce equation (2.13) to one involving $L_{r}$ and $K_{r}$. However until Section 5, we shall assume that both $p_{f}$ and $p_{m}$ are exogenously given. This allows us to understand the basic structure and properties of the model without bringing in the complications of changes in the terms of trade. Once these basic properties are clear, it is a simpler matter to allow for such changes.

Equation (2.12) states simply that the marginal rate of substitution between capital and the primary resource is equal in equilibrium to the marginal product of capital in the production of the resource. Such an equilibrium is depicted in Figure 1 where the curve OA represents the production function of the primary resource under a given value of the labour input $L_{r}$. The other lines in Figure 1 represent the isoquant map for Industrian manufactures but it is worth noting that each isoquant implies a particular value of $L_{r}$ and at the point $\mathrm{E}$, this value is identical to the one which parametrizes OA. As pointed out by Ron Findlay, Figure 1 completely characterizes the equilibrium in the Kemp-Ohyama set-up. In our context, it enables us to determine only a locus in the $L_{r}-K_{r}$ plane. To determine the slope of such a

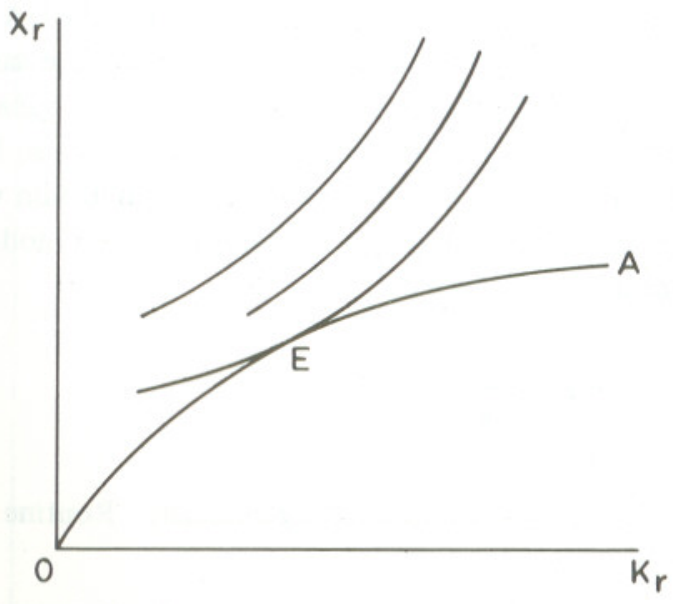

Figure 1. Equilibrium in the Capital Market

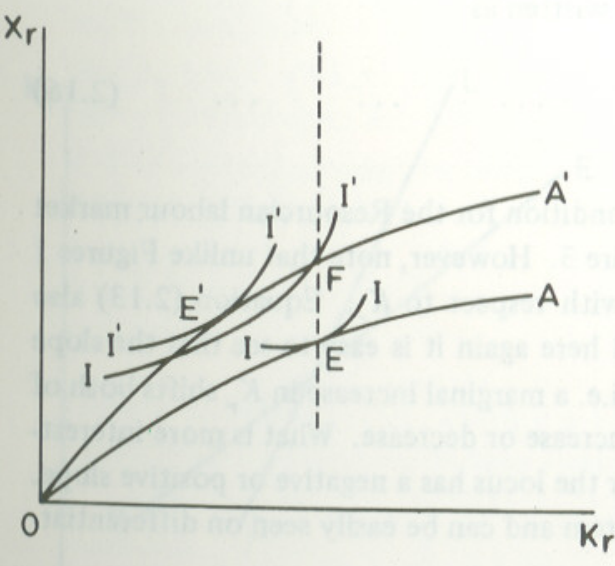

Figure 2a. $\xi<0$

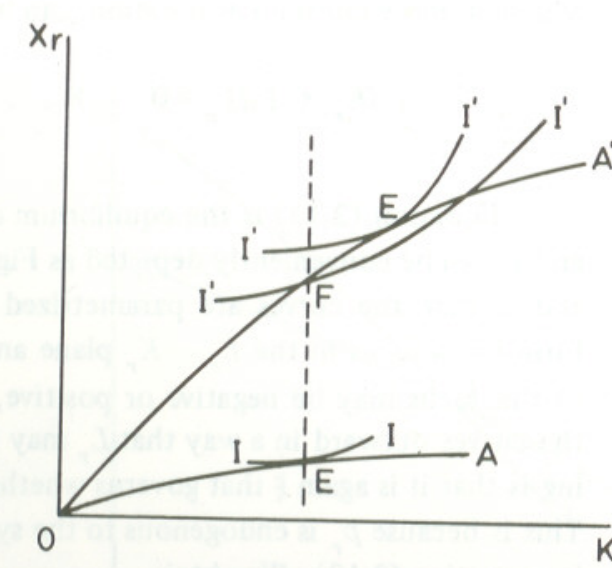

Figure 2b. $\xi>0$ $\mathrm{kr}_{\mathrm{r}}$ 
locus, we have to see how the value of $K_{r}$ corresponding to the point E responds to marginal changes in $L_{r}$. It is clear that such a change shifts the OA curve outward in a manner that its slope at any given value of $K_{r}$ increases. The same is true of our isoquant map - it too shifts outward in such a way that the marginal rate of substitution at any given value of $K_{r}$ increases. Such shifts are shown in Figures 2a and $2 \mathrm{~b}$ and they can lead to an increase or a decrease in the equilibrium value of $K_{r}$. The parameter governing this change will play a crucial role for our model, and as the preceding discussion indicates, it is given by

$$
\xi=\frac{\partial \log \left(F_{r}^{2} F_{m}^{3} / F_{m}^{2}\right)}{\partial L_{r}} \quad \ldots \quad \ldots
$$

All this can, of course, be established algebraically. Routine differentiation of equation (2.12) yields

$$
\begin{array}{r}
d K_{r}\left[-\frac{F_{m}^{32}}{F_{m}^{3}}+\frac{F_{r}^{2} F_{m}^{33}}{F_{m}^{3}}+\frac{F_{r}^{22}}{F_{r}^{2}}+\frac{F_{m}^{22}}{F_{m}^{2}}-\frac{F_{m}^{23} F_{r}^{2}}{F_{m}^{2}}\right]+d L_{r} \\
{\left[\frac{F_{r}^{21}}{F_{r}^{2}}+\frac{F_{m}^{33} F_{r}^{1}}{F_{m}^{3}}-\frac{F_{m}^{23} F_{r}^{1}}{F_{m}^{2}}\right]=0 \quad \ldots \quad \ldots \quad \ldots}
\end{array}
$$

which, in more convenient notation, can be written as

$$
\begin{array}{llllll}
A d K_{r}+\xi d L_{r}=0 & \ldots & \ldots & \ldots & \ldots
\end{array}
$$

Equation (2.13) is the equilibrium condition for the Resourcian labour market and it can be conveniently depicted as Figure 3. However, note that unlike Figures 1 and 2, here the curves are parametrized with respect to $K_{r}$. Equation (2.13) also furnishes a locus in the $L_{r}-K_{r}$ plane and here again it is easy to see that the slope of this locus may be negative or positive, i.e. a marginal increase in $K_{r}$ shifts both of the curves outward in a way that $L_{r}$ may increase or decrease. What is more interesting is that it is again $\xi$ that governs whether the locus has a negative or positive slope. This is because $p_{r}$ is endogenous to the system and can be easily seen on differentiating equation (2.13). We obtain

$$
d K_{r}\left[-\frac{F_{m}^{32}}{F_{m}^{3}}+\frac{F_{m}^{33}}{F_{m}^{3}} F_{r}^{2}+\frac{F_{r}^{12}}{F_{r}^{1}}\right]+d L_{r}\left[\frac{F_{r}^{11}}{F_{r}^{1}}+\frac{F_{f}^{11}}{F_{f}^{1}}+\frac{F_{r}^{1} F_{m}^{33}}{F_{m}^{3}}\right]=0
$$

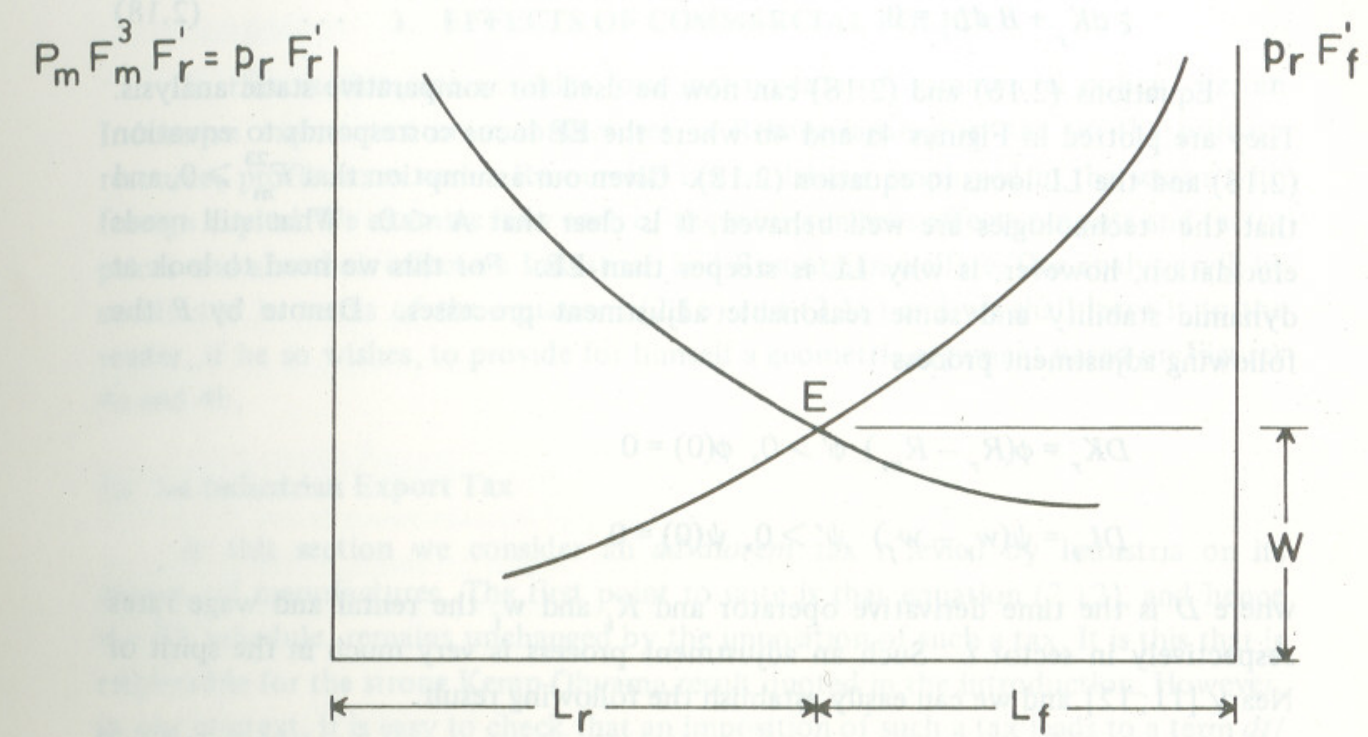

Figure 3. Equilibrium in the Labour Market
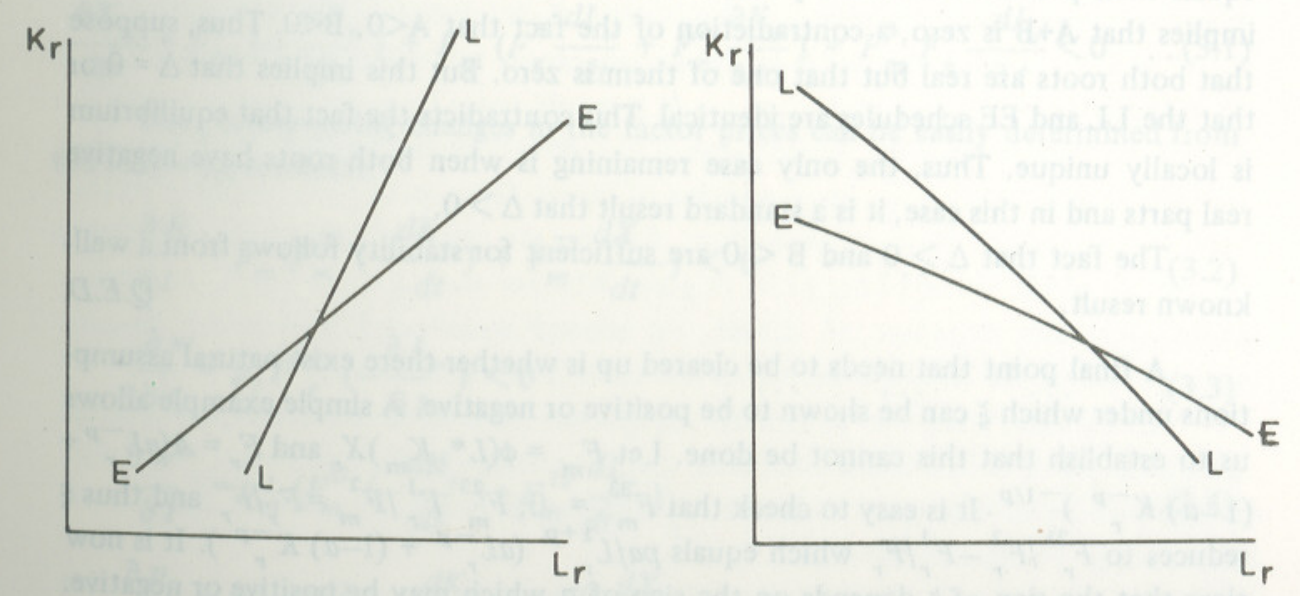

Figure 4a. $\xi>0$ 


$$
\xi d K_{r}+B d L_{r}=0 \quad \ldots \quad \ldots \quad \ldots \quad \ldots
$$

Equations (2.16) and (2.18) can now be used for comparative static analysis. They are plotted in Figures $4 \mathrm{a}$ and $4 \mathrm{~b}$ where the EE locus corresponds to equation (2.16) and the LL locus to equation (2.18). Given our assumption that $F_{m}^{23} \geqslant 0$, and that the technologies are well behaved, it is clear that $\mathrm{A}<0$. What still needs elucidation, however, is why LL is steeper than EE. For this we need to look at dynamic stability and some reasonable adjustment processes. Denote by $P$ the following adjustment process

$$
\begin{aligned}
& D K_{r}=\phi\left(R_{r}-R_{m}\right) \phi^{\prime}>0, \phi(0)=0 \\
& D L_{r}=\psi\left(w_{r}-w_{f}\right) \quad \psi^{\prime}>0, \psi(0)=0
\end{aligned}
$$

where $D$ is the time derivative operator and $R_{i}$ and $\mathrm{w}_{i}$ the rental and wage rates respectively in sector $i$. Such an adjustment process is very much in the spirit of Neary $[11 ; 12]$ and we can easily establish the following result.

Proposition I: A locally unique equilibrium is locally asymptotically stable under the adjustment process $P$ if and only if $A B-\xi^{2} \equiv \triangle>0$.

Proof: It is well known that under local asymptotic stability, none of the eigenvalues of the matrix obtained by linearization of $P$ can have positive real parts. Suppose one, and therefore both, have a zero real part and can be written as $\pm \beta i$. Then $\Delta$ equals their product which is a positive number. The sum of the roots is zero which implies that $\mathrm{A}+\mathrm{B}$ is zero, a contradiction of the fact that $\mathrm{A}<0, \mathrm{~B}<0$. Thus, suppose that both roots are real but that one of them is zero. But this implies that $\Delta=0$ or that the LL and EE schedules are identical. This contradicts the fact that equilibrium is locally unique. Thus, the only case remaining is when both roots have negative real parts and in this case, it is a standard result that $\Delta>0$.

The fact that $\Delta>0$ and $\mathrm{B}<0$ are sufficient for stability follows from a wellknown result.

Q.E.D.

A final point that needs to be cleared up is whether there exist natural assumptions under which $\xi$ can be shown to be positive or negative. A simple example allows us to establish that this cannot be done. Let $F_{m}=\phi\left(L^{*}, K_{m}\right) X_{r}$ and $F_{r}=A\left(a L_{r}^{-p}+\right.$ $\left.(1-a) K_{r}^{-p}\right)^{-1 / p}$. It is easy to check that $F_{m}^{33}=0, F_{m}^{23} F_{r}^{1} / F_{m}^{2}=F_{r}^{1} / F_{r}$ and thus $\xi$ reduces to $F_{r}^{21} / F_{r}^{2}-F_{r}^{1} / F_{r}$ which equals $p a / L_{r}^{1+p}\left(a L_{r}^{-p}+(1-a) K_{r}^{-p}\right)$. It is now clear that the sign of $\xi$ depends on the sign of $p$ which may be positive or negative. Indeed, for a Cobb-Douglas world, $p$ and, therefore, $\xi$ are zero. In this case EE is a horizontal line and LL a vertical one. In the sequel, we shall leave it to the reader to see how our results apply to this degenerate case.

\section{EFFECTS OF COMMERCIAL POLICY}

In this section, we consider four instruments of commercial policy, viz. an Industrian export tax on manufactures, a Resourcian export tax on the primary resource, profit taxes and a Resourcian tax on labour employed in the sector with foreign capital. We examine how each of these instruments affects outputs and factor prices and also their effect on Industrian and Resourcian welfare. Our analysis will be conducted in terms of the equations (2.16) and (2.18) and we shall leave it to the reader, if he so wishes, to provide for himself a geometric argument based on Figures $4 \mathrm{a}$ and $4 \mathrm{~b}$.

\section{(i) An Industrian Export Tax}

In this section we consider an advalorem tax $t$ levied by Industria on its exports of manufactures. The first point to note is that equation (2.12), and hence the EE schedule, remains unchanged by the imposition of such a tax. It is this that is responsible for the strong Kemp-Ohyama result quoted in the introduction. However, in our context, it is easy to check that an imposition of such a tax leads to a term $d t /$ $(1-t)$ on the right hand side of equation (2.17) and hence causes the LL schedule to move to the left in both Figures $4 \mathrm{a}$ and $4 \mathrm{~b}$.

Let us first consider the case when $\xi>0$. Here both $L_{r}$ and $K_{r}$ fall leading to a contraction in the output of the primary resource and an expansion of the output of food. The change in manufactures can be easily determined by

$$
\frac{\partial X_{m}}{\partial t}=F_{m}^{2}\left(-\frac{d K_{r}}{d t}\right)+F_{m}^{3}\left(F_{r}^{1} \frac{d L_{r}}{d t}+F_{r}^{2} \frac{\partial K_{r}}{\partial t}\right)=F_{m}^{3} F_{r}^{1} \frac{d L_{r}}{\partial t}<0
$$

The corresponding changes in the factor prices can be easily determined from the following formulae.

$$
\begin{aligned}
& \frac{\partial R}{\partial t}=p_{m}\left(F_{m}^{22}\left(-\frac{d K_{r}}{d t}\right)+F_{m}^{23} \frac{d X_{r}}{d t}\right)<0 \quad \ldots \quad \ldots
\end{aligned}
$$

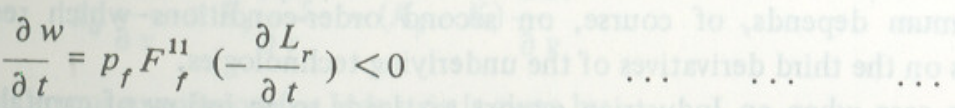

$$
\begin{aligned}
& \frac{\partial w^{*}}{\partial t}=p_{m}\left(F_{m}^{12}\left(-\frac{d K_{r}}{d t}\right)+F_{m}^{13} \frac{d L_{r}}{d t}\right) \quad \ldots \ldots \\
& \frac{\partial p_{r}}{\partial t}=p_{m}\left(F_{m}^{32}\left(-\frac{d K_{r}}{d t}\right)+F_{m}^{33} \frac{d X_{r}}{d t}\right)
\end{aligned}
$$

We now consider the implications of an export tax on Resourcian and Industrian welfare. Let us assume that Resourcia is a borrower of foreign capital and let Resourcian welfare be measured by a quasi-concave utility function $U(\cdot)$ which is 
defined on Resourcian consumption $\left(Z_{m}, Z_{t}\right)$. Let $g_{r}\left(p_{m}, p_{f}, U\right)$ be the minimum expenditure ${ }^{6}$ at prices $p_{m}$ and $p_{f}$ required to reach the utility level $U$. We can then write the Resourcian income/expenditure identity as

$$
g\left(p_{m}, p_{f}, u\right)=p_{r} X_{r}+p_{f} X_{f}-R\left(K_{r}-K\right)=w L_{r}+p_{f} X_{f}+R K \quad \ldots
$$

On differentiating identity (3.6), we obtain ${ }^{7}$

$$
g_{0} \frac{\partial u}{\partial t}=L_{r} \frac{\partial w}{\partial t}+K \frac{\partial R}{\partial t}
$$

Given equations (3.2) and (3.3), it is clear that we have obtained the Kemp-Ohyama result that Resourcian welfare always decreases with an increase in an Industrian export tax. However, what is interesting is that it is now no longer in the interest of Industria to keep on increasing this tax. To see this, consider the analogue of equation (3.6) for Industria, i.e.

$$
g^{*}\left(p_{m}(1-t), p_{f}, u^{*}\right)=p_{m}(1-t) X_{m}+R\left(K_{r}-K\right)-p_{r} X_{r}+p_{m} t\left(X_{m}-g_{1}^{*}\right)
$$

On differentiating equation (3.8) and collecting terms, we obtain

$$
g_{0}^{*}\left(1+\frac{m t}{1-t}\right) \frac{\partial u^{*}}{\partial t}=-p_{m}^{2} t g_{11}^{*}+\left(K_{r}-K\right) \frac{d R}{d t}+p_{m} t \frac{\partial X_{m}}{\partial t}-X_{r} \frac{\partial p_{r}}{\partial t}
$$

where $m$ is the marginal propensity to consume the exported commodity. Given that $K_{r}, R$ and $X_{m}$ all decrease with an Industrian export tax, we can now see that from an initial position of free trade, i.e. $t=0$, it would never be in Industria's interest to impose an export tax even though such a tax would be detrimental for Resourcian welfare. Indeed, at such an initial position of laissez-faire, an export subsidy increases both Industrian and Resourcian welfare. At any rate, an optimal value of an export tax can be found on equating (3.9) to zero. Whether such a value is unique and is a global optimum depends, of course, on second order-conditions which require assumptions on the third derivatives of the underlying technologies.

In the case when an Industrian export tax leads to an inflow of capital into Resourcia, i.e. $\xi<0$, it is not even clear that Resourcian welfare decreases. Note that in this case $X_{r}$ falls in spite of increased foreign investment. It is easy to check from equations (2.16) and (2.18) that

$$
\frac{\partial K_{r}}{\partial t}=-\xi / \Delta, \frac{\partial L_{r}}{\partial t}=A / \Delta
$$

${ }^{6}$ It is well known (see, for example Gorman [4]) that $\partial$ is (i) positively homogeneous of degree 1 in prices, (ii) concave function of the prices, and (iii) $\partial g / \partial p_{i}$ is the consumption of the $i$ th commodity.

$$
\begin{aligned}
& { }^{7} g_{0} \text { is the differential of } g \text { with respect to } u \text { and represents the inverse of the marginal } \\
& \text { of income. }
\end{aligned}
$$

and consequently

$$
\frac{\partial X_{r}}{\partial t}=\frac{F_{r}^{2}}{\Delta} \quad\left[-\xi+\frac{F_{r}^{1}}{F_{r}^{2}} A\right]<0 \quad \ldots \quad \ldots
$$

It is now clear from equation (3.2) that $\partial R / \partial t$ may not necessarily fall and therefore from equation (3.7), $\frac{\partial u}{\partial t}$ may increase.

In concluding this section, it is useful to observe that an Industrian export tax decreases the welfare of Resourcian labour irrespective of the value of $\xi$.

\section{(ii) A Resourcian Export Tax}

A Resourcian ad valorem export tax at the rate $v$ results in equation (2.10) remaining unchanged but with $p_{r}(1-v)$ being substituted for $p_{r}$ in equations (2.9) and (2.11). This leads to a term $d v /(1-v)$ on the right hand side of each of equations (2.16) and (2.18) and we obtain

$$
\frac{\partial K_{r}}{\partial v}=\frac{B-\xi}{(1-v) \Delta} ; \frac{\partial L_{r}}{\partial v}=\frac{A-\xi}{(1-v) \Delta} \quad \cdots \quad \ldots
$$

As in Section 3(i), let us begin by considering the case $\xi>0$. Here the LL schedule shifts upwards and the EE schedule downwards so as to decrease the equilibrium values of both $L_{r}$ and $K_{r}$ and consequent contraction of $X_{r}$ and $X_{m} . X_{f}$ increases and equations (3.2) to (3.5) remain as before but with $v$ substituted for $t$. If the revenue from the export tax is distributed in a lump-sum fashion, Resourcian welfare is implicitly defined by

$$
g\left(p_{m}, p_{f}, u\right)=p_{r}(1-v) X_{r}+p_{r} v X_{r}+p_{f} X_{f}-R\left(K_{r}-K\right) \quad \ldots
$$

which on differentiation yields

$$
g_{0} \frac{\partial u}{\partial v}=X_{r} \frac{\partial p_{r}}{\partial v}-\left(K_{r}-K\right) \frac{\partial R}{\partial v}
$$

An analogous expression for Industria is given by

$$
g_{0}^{*} \frac{\partial u^{*}}{\partial v}=-X_{r} \frac{\partial p_{r}}{\partial v}+\left(K_{r}-K\right) \frac{\partial R}{\partial v}
$$

We thus obtain the interesting result that at least for the case $\xi>0$, there is no limit to the extent to which Resourcia can exploit Industria by means of a single instrument - a tax on the export of the primary resource. On viewing this result in conjunction with that of Section 3(i), we can observe that there is indeed asymmetry in the bargaining position of the two countries but in a direction opposite to that asserted by Kemp-Ohyama. 
For the case $\xi<0$, the EE and LL schedules shift in a way that the direction of $L_{r}$ and $K_{r}$ cannot be determined without additional assumptions on technology. The kind of assumptions that one will need are clear from the formulae in equation (3.12). It is, of course, possible in this case that there is an optimal value at which Resourcia should set its export tax.

\section{(iii) A Tax on Capital}

Now let us suppose that Resourcia imposes an ad valorem $\operatorname{tax} \tau$ on the earnings of foreign capital. It is clear that this keeps equation (2.18) unchanged but results in a term $d \tau /(1-\tau)$ on the right hand side of equation (2.16). We can therefore conclude that

$$
\frac{\partial K_{r}}{\partial \tau}=\frac{B}{\Delta(1-\tau)} ; \frac{\partial L_{r}}{\partial \tau}=\frac{-\xi}{\Delta(1-\tau)} \quad \ldots \quad \ldots
$$

Thus a Resourcian tax on foreign capital always decreases foreign investment. In the case $\xi>0, L_{r}$ and consequently $X_{r}$ and $X_{m}$ both decrease. Again, equations (3.2) to (3.5) remain unchanged but with $\tau$ substituted for $t$. Resourcian welfare is now given by

$$
g\left(p_{m}, p_{f}, u\right)=p_{r} X_{r}+p_{f} X_{f}-(1-\tau) R\left(K_{r}-K\right) \ldots
$$

On differentiating this with respect to $\tau$, we obtain

$$
g_{0} \frac{\partial u}{\partial \tau}=R\left(K_{r}-K\right)-(1-\tau)\left(K_{r}-K\right) \frac{\partial R}{\partial \tau}+\tau R \frac{\partial K_{r}}{\partial \tau} \quad \ldots
$$

It is now clear that in the case under consideration, i.e. $\xi>0$, a restriction of capital imports from an initial position of laissez-faire is in Resourcia's interest. Indeed, the optimal tax is given by

$$
\tau^{o p t}=\frac{\left(K_{r}-K\right)(R-\partial R / \partial \tau)}{-\left(R \partial K_{r} / \partial \tau+\left(K_{r}-K\right) \partial R / \partial \tau\right)} \quad \ldots \quad \ldots
$$

and is clearly a positive number. If we let

$$
\epsilon_{R}=\frac{\partial \log R}{\partial \log \tau}, \epsilon_{K}=\frac{\partial \log K_{r}}{\partial \log \tau}
$$

we can rewrite equation (3.19) in more conventional terms as

$$
\tau^{o p t}=\frac{\epsilon_{R}}{1+\epsilon_{R}+\epsilon_{K}}
$$

Industrian welfare, on the other hand, is now given by

$$
g^{*}\left(p_{m}, p_{f}, u^{*}\right)=p_{m} X_{m}+(1-\tau) R\left(K_{r}-K\right)-p_{r} X_{r} \quad \ldots
$$

and it is clear that

$$
g_{0}^{*} \frac{\partial u^{*}}{\partial \tau}=-\tau R \frac{\partial K_{r}}{\partial \tau}+(1-\tau)\left(K_{r}-K\right) \frac{d R}{\partial \tau}-X_{r} \frac{d p_{r}}{\partial \tau}-R\left(K_{r}-K\right)
$$

we can thus conclude that from an initial position of laissez-faire, an imposition of a Resourcian tax on foreign earnings is detrimental to Industria. If there is already such a tax in existence, an increase in it yields a saving to Industria of the amount of its capital earnings not taxed away by Resourcia, i.e. $\tau R \partial K_{r} / d t$.

We can also consider a situation in which Industria taxes the foreign earnings of its capital in Resourcia. If the proceeds of such a tax are redistributed in a lumpsum fashion to Industrian residents, Industrian welfare is given by

$$
g^{*}\left(p_{m}, p_{f}, u^{*}\right)=p_{m} X_{m}+R\left(K_{r}-K\right)-p_{r} X_{r} \quad \ldots \quad \ldots
$$

Resourcian welfare, of course, is determined by

$$
g\left(p_{m}, p_{f}, u\right)=p_{r} X_{r}+p_{f} X_{f}-R\left(K_{r}-K\right) \quad \ldots \quad \ldots
$$

On differentiating each of these expressions, we obtain

$$
\begin{aligned}
& g_{0}^{*} \frac{\partial u^{*}}{\partial \tau^{*}}=-X_{r} \frac{\partial p_{r}}{\partial \tau^{*}}+\left(K_{r}-K\right) \frac{\partial R}{\partial \tau^{*}} \quad \ldots . \quad \ldots \\
& g_{0} \frac{\partial u}{\partial \tau^{*}}=-\left(K_{r}-K\right) \frac{\partial R}{\partial \tau^{*}}+X_{r} \frac{\partial p_{r}}{\partial \tau^{*}}
\end{aligned}
$$

It is clear that the allocative effects of an Industrian $\operatorname{tax} \tau^{*}$ are identical to that of a Resourcian tax on foreign capital - only the tax proceeds fall in different hands. We then obtain, in the case $\xi>0$, the result that an increase in $\tau^{*}$ is always detrimental to Industrian welfare but beneficial for Resourcia. Of course, in this case, a subsidy to the earnings of its capital abroad would have opposite effects.

\section{(iv) A Tax on Labour}

In this subsection we consider the consequences of a tax on Resourcian labour employed in the primary resource sector. In this case equation (2.16) remains unchanged but we have to add a term $d s /(1-s)$ on the right hand side of equation (2.18), where $s$ is the ad valorem rate of the tax. It is now clear that the LL schedule shifts so that 


$$
\frac{\partial K_{r}}{\partial s}=\frac{-\xi}{\Delta(1-s)}, \frac{\partial L_{r}}{\partial s}=\frac{A}{\Delta(1-s)}
$$

In the case $\xi>0$, an increase in a tax on labour decreases the amount of foreign capital in Resourcia and results in a decrease of both $X_{r}$ and $X_{m}$. On appealing to equations (3.2) to (3.5) with $s$ substituted for $t$, we deduce that $R$ and $w$ fall and $P_{r}$ rises. The change in the position of Industrian labour is ambiguous and depends on how the marginal product of labour in Industrian manufacturing responds to changes in capital and the primary resource.

In the case $\xi<0$, an increase in the rate of tax increases the amount of foreign capital in Resourcia. The change in $X_{r}$ is given by

$$
\frac{\partial X_{r}}{\partial s}=\frac{F_{r}^{2}}{\Delta(1-s)}\left(A \frac{F_{r}^{1}}{F_{r}^{2}}-\xi\right)<0
$$

Resourcian wages fall but the rental may increase. A sufficient condition for such an increase is simply that the marginal product of capital in Industrian manufacturing be independent of the amount of the primary resource.

These results may be usefully compared with the corresponding ones of Jones and Dei who argue that the rental always falls and that the wages always rise in the country not imposing the tax.

Finally, we consider the effect of such a tax on welfare. In the case of Resourcia, we obtain

$$
g_{0} \frac{\partial u}{\partial s}=X_{r} \frac{\partial p_{r}}{\partial s}+L_{r} w+L_{r} s \frac{d w}{d s}-\left(K_{r}-K\right) \frac{\partial R}{\partial s}
$$

Thus, in the case $\xi>0$, on starting from a position of laissez-faire, it is always in Resourcia's interest to restrict the employment of its nationals in the sector with foreign capital. Indeed, the optimum rate of such a tax is positive as can be seen easily on equating $\partial u / \partial s$ to zero.

In the case of Industria, we have

$$
g^{*}\left(p_{m}, p_{f}, u^{*}\right)=p_{m} X_{m}+R\left(K_{r}-K\right)-p_{r} X_{r} \ldots
$$

from which we can obtain

$$
g_{0}^{*} \frac{\partial u^{*}}{\partial s}=-X_{r} \frac{\partial p_{r}}{\partial s}+\left(K_{r}-K\right) \frac{\partial R}{\partial s}
$$

It is easily seen that in the case $\xi>0$, Industrian welfare decreases without limit.

\section{OPTIMAL COMMERCIAL POLICY}

So far, our concern has been with particular instruments of commercial policy. We have examined how each of these affects outputs, the distribution of income and welfare. We also deduced the optimal values of these instruments from the viewpoint of national advantage. In this section we adopt a different and, in some sense, an opposite point of view. We focus here instead on each country's welfare and ask what instruments, and the values of these instruments, are required to maximize it. From this angle, the optimal policies of Section 3 may be looked on as second-best ${ }^{8}$ policies since the choice of instrument has already been determined and one is trying to accomplish with a single instrument what, as we shall see below, typically requires two.

The first point to be noted is that with exogenously given prices of food and manufacturing, $p_{m}$ and $p_{f}$, the optimal policy for Industrian and Resourcian welfare taken together is a position of laissez-faire. Of course, this is intuitively clear since there are no distortions or a monopoly advantage to be taken care of. In any case, this can be easily seen on examining the first-order conditions for the problem.

$$
\begin{array}{ll}
\text { Maximize } p_{m} F_{m}+p_{f} F_{f} \\
\text { subject to } & L_{r}+L_{f}=L \\
& K_{r}+K_{m}=K
\end{array}
$$

It is clear that the necessary conditions are precisely those given in equations (2.9) and (2.11).

The position is totally changed when we consider each country on its own. Industrian welfare is maximized on solving the following problem.

$$
\begin{aligned}
& \text { Maximize } p_{m} F_{m}\left(L^{*}, K_{m}, M\right)-p_{r} M+R\left(K^{*}-K_{m}\right) \quad \cdots \\
& M, K_{m}
\end{aligned}
$$

If Industria is to take $p_{r}$ and $R$ as exogenously given, the market solution is optimal for it and there is little more to be done. The point, of course, is that Industria realizes that both $p_{r}$ and $R$ depend on the amount of the primary resource and capital that it uses. Specifically, on the assumption of a passive Resourcia, these are given by

$$
p_{r}=p_{m} F_{m}^{3} ; R=p_{r} F_{r}^{2}\left(L_{r}, K-K_{m}\right)
$$

${ }^{8}$ Indeed, as Brecher points out in a different context, such policies are third-best if consumption taxes are allowed. 
It is this observation that calls for interference with the laissez-faire solution. The nature of such an interference can be easily seen on examining the necessary conditions for equation (4.1), with equation (4.2) being appropriately substituted. We obtain

$$
\begin{aligned}
& p_{m} F_{m}^{3}-p_{r}-p_{m} M F_{m}^{33}+\left(K^{*}-K_{m}\right) F_{r}^{2} p_{m} F_{m}^{33}=0 \\
& p_{m} F_{m}^{2}-R-p_{m} M F_{m}^{32}-\left(K^{*}-K_{m}\right)\left(p_{r} F_{r}^{22}-F_{r}^{2} p_{m} F_{m}^{32}\right)=0
\end{aligned}
$$

On simplifying these expressions, we obtain

$$
\begin{aligned}
& p_{r}=p_{m} F_{m}^{3}\left[1-\frac{M F_{m}^{33}}{F_{m}^{3}}\left(1-\left(K_{r}-K\right) \frac{F_{r}^{2}}{F_{r}}\right)\right] \quad \ldots \quad \quad \ldots \\
& R\left[1+\left(K^{*}-K_{u}\right)\left(\frac{F_{r}^{22}}{F_{r}^{2}}-\frac{F_{m}^{32}}{F_{m}^{3}}\right)\right]=p_{m} F_{m}^{2}\left(1-\frac{M F_{m}^{32}}{F_{m}^{2}}\right) \quad \cdots
\end{aligned}
$$

It is now clear that optimal policy for Industria calls for an import subsidy on the primary resource and also interference in the international capital market. If the marginal product of capital is independent of the amount of the primary resource, i.e. $F_{m}^{32}=0$, such an interference takes the form of a subsidy to capital used in Industria, or alternatively, a tax on the earnings of capital in Resourcia. Thus, at least in this case, the optimal policy of Industria involves encouragement to the production of the primary resource. Such an encouragement takes the form of furnishing a higher price for it as well as in subsidizing one of its inputs. In the case when $M F_{m}^{32} / F_{m}^{2}>1$, it is no longer clear whether capital at home should be taxed or subsidized.

An alternative set of first-best commercial policies for Industria is a production subsidy on manufacturing accompanied by a tax or subsidy on the earnings of capital at home. It is worth pointing out that the result is consistent with the corresponding result of Section 2 that an Industrian production tax is not necessarily beneficial for Industrian welfare. It is also useful to note that, unlike Kemp-Ohyama, no single instrument suffices for the maximization of Industrian welfare.

We now turn to Resourcia. Its optimal set of commercial policies may be found on solving the following program.

Maximize $p_{r} F_{r}+p_{f} X_{f}-R\left(K_{r}-K\right)$

subject to $L_{r}+L_{f}=L$
As before, Resourcia has little reason to interfere with the market solution if it considers $p_{r}$ and $R$ as being beyond its control. It is only under the assumption of a passive Industria and the fact that

$p_{r}=p_{m} F_{m}^{3}\left(L^{*}, K-K_{r}, F_{r}\left(L_{r}, K_{r}\right)\right), R=p_{m} F_{m}^{2}\left(L^{*}, K-K_{r}, F_{r}\left(L_{r}, K_{r}\right)\right)$

that optimal interference in the markets for capital and the resource is called for.

On solving equation (3.7), with equation (3.8) appropriately substituted, we obtain

$$
\begin{aligned}
& p_{r} F_{r}^{1}+p_{m} F_{r} F_{m}^{33} F_{r}^{1}+\left(K-K_{r}\right) p_{m} F_{m}^{23} F_{r}^{1}=w=p_{f} F_{f}^{1} \quad \ldots \\
& p_{r} F_{r}^{2}-R+p_{m} F_{r}\left(F_{m}^{33} F_{r}^{2}-F_{m}^{32}\right)+\left(K-K_{r}\right) p_{m}\left(F_{m}^{23} F_{r}^{2}-F_{m}^{22}\right)=0
\end{aligned}
$$

On simplifying these expressions, we obtain

$$
\begin{gathered}
w=p_{r} F_{r}^{1}\left(1+\frac{F_{r} F_{m}^{33}}{F_{m}^{3}}+\left(K-K_{r}\right) \frac{F_{m}^{23}}{F_{m}^{3}}\right) \quad \ldots \\
R=p_{r} F_{r}^{2}\left[1+\frac{F_{r}}{F_{m}^{3}}\left(F_{m}^{33}-\left(F_{m}^{32} / F_{r}^{2}\right)\right)+\frac{\left(K-K_{r}\right)}{F_{m}^{3}}\left(F_{m}^{23}-\left(F_{m}^{22} / F_{r}^{2}\right)\right)\right]
\end{gathered}
$$

It is now clear that optimal policy for Resourcia calls for the taxation of foreign capital as well as taxation of the earnings of labour employed in the sector with foreign capital. It is interesting that this result has affinity with a point first made by Kemp and Negishi [9] and later generalized by Bhagwati, Ramaswami and Srinivasan [1]. These authors argue that tariffs could be used to improve the welfare of a country suffering from a distortion in the labour market; in the case at hand one arising from a wage differential. Here we find that a country may exploit it monopoly power in trade by resorting to the first-best policy of introducing a wage differential in the labour market.

An alternative set of optimal policies for Resourcia is a production tax on the primary resource along with a subsidy on foreign capital.

We conclude this section by pointing out that in the Jones-Dei model $F_{m}^{3}=0$ and the optimal policy for Resourcia in that context calls for a restriction on the international flow of capital. For Industria, the optimal policy is to subsidize the outflow of international capital. Of course, this result, as indeed all the others in this section, is based on the premise that Resourcia is a borrower of Industrian capital.

\section{ENDOGENOUS TERMS OF TRADE}

Our analysis has benefited so far from the simplifying assumption of exogenously given prices of food and manufactures. Such an assumption allowed us 
to focus on international capital movements and the market for the intermediate input without bringing in the complications arising out of changes in the terms of trade of the final products. While it is clear that even with such an assumption our model has relevance for many problems, exogenously given prices have no place in a North-South model. Fortunately, the analysis remains tractable even with endogenous terms of trade.

Let manufactures by the numeraire commodity and the inverse demand function for food be given by

$$
p_{f}=\phi\left(X_{f}\right) \phi^{\prime}(\cdot)<0 \quad \ldots \quad \ldots
$$

Since only one of our basic equations, (2.13), involves the price of food, equation (2.16) and the corresponding EE schedule remain unchanged. In the context of the LL schedule, equation (2.18) is modified so that $B$ is substituted by $B^{\prime}$ where

$$
B^{\prime}=B-\left(\phi^{\prime} F_{f}^{\prime} / \phi\right) \quad \ldots \quad \ldots
$$

Thus, in the context of the comparative statics exercises presented in Section 3, our earlier assumption that $B$ be negative has to be strengthened to the requirement that $B$ be negative. However, this follows from the stability result of Section 2 where the dynamic process $p$ now takes account of the fact that $p_{f}$ is endogenous. With these modifications, the allocative effects of the various instruments of commercial policy remain unchanged, as do the results on Industrian welfare. However, the results on Resourcian welfare require a routine modification involving the elasticity of the world demand for food. For example, in the context of an Industrian export tax, differentiation of equation (3.6) yields

$$
g_{0} \frac{\partial u}{\partial t}=L_{r} \frac{\partial w}{\partial t}+E_{f} \phi^{\prime} \frac{\partial X_{f}}{\partial t}+K \frac{\partial R}{\partial t} \quad \ldots \quad \ldots
$$

where $E_{f}$ is the food exports to Industria. Thus, in the case $\xi>0$, the term-of-trade effect merely strengthens our earlier result that an increase in an Industrian export tax decreases Resourcian welfare.

Of course, the question arises as to what happens if food rather than manufacturing is the numeraire commodity. In this case, our results concerning Industrian welfare require modification in the light of changes in the terms of trade. However, more importantly, in the context of equation (2.18), both $\xi$ and $B$ require modifications. This results in the coefficient of $d K_{r}$ in equation (2.18) being different from that of $d L_{r}$ in equation (2.16) and prevents a stability result as clean as in the Proposition of Section 2. This also results in the various cases becoming interchanged in the context of our comparative statics results. Nevertheless, the basic insights emerging from our model carry over. It is worth stating that this sensitivity to the choice of the numeraire is the direct consequence of the asymmetric production structure of our model.

It is when we turn to questions of optimal commercial policy that relaxation of the assumption of exogenously given terms of trade becomes most interesting. It is at this stage that we make contact with the standard theory of optimal commercial policy as developed by Jones [5] and Kemp [8]

Let the Industrian consumption of manufactures and food be denoted by $\left(C_{m}^{*}, C_{f}^{*}\right)$ and that of Resourcia by $\left(C_{m}, C_{f}\right)$. The first-best policy for Industria is obtained on maximizing $U^{*}\left(C_{m}^{*}, C_{f}^{*}\right)$ subject to

$$
\begin{array}{lllll}
C_{m}^{*}=F_{m}-C_{m} & \ldots & \ldots & \ldots & \ldots \\
C_{f}^{*}=R\left(K^{*}-K_{u}\right)-p_{r} M+p_{m} C_{m} & \ldots & \ldots & \ldots
\end{array}
$$

with $K_{u}, M$ and $p_{m}$ as the relevant control variables. On letting $q_{m}\left(=U_{m}^{*} / U_{f}^{*}\right)$ be the price ratio faced by Industrian consumers, it is easy to derive the following necessary conditions.

$$
\begin{gathered}
q-p_{m}=\frac{C_{m}-F_{r} F_{m}^{3}\left(1-\left(K^{*}-K_{u}\right) F_{r}^{2} / F_{r}\right)}{C_{m p}} \ldots \\
R\left[1+\left(K^{*}-K_{u}\right)\left(\frac{F_{r}^{22}}{F_{r}^{2}}-\frac{F_{m}^{32}}{F_{m}^{3}}\right)\right]=q F_{m}^{2}-\left(q-p_{m}\right) C_{m I} \frac{\partial I}{\partial K_{u}} \\
p_{r}=q F_{m}^{3}-M p_{m} F_{m}^{33}\left(1-\left(K^{*}-K_{u}\right) F_{r}^{2} / F_{r}\right)-\left(q-p_{m}\right) C_{m I} \frac{\partial I}{\partial M}
\end{gathered}
$$

$C_{m p}$ denotes the change in the Resourcian demand for manufacturing corresponding to the change in the price of manufacturing. In the absence of any inferiority in consumption $C_{m p}<0 . C_{m I}$ is the change in the demand corresponding to a change in the Resourcian income and is assumed positive. It is important to be clear as to how the change in Resourcian incomes are brought about. Note that Industria is exploiting the fact that $p_{r}$ and $R$ respond to changes in $K_{u}, M$. Since Resourcian income $I$ is given by

$$
I=p_{r} F_{r}+F_{f}-R\left(K^{*}-K_{u}\right) \quad \ldots \quad \ldots
$$

it is easy to check that both $\partial I / \partial M$ and $\partial I / \partial K_{u}$ are positive. 
We now get on to the optimal policy formulae themselves. They can most usefully be compared with the corresponding equations (4.5) and (4.6) which are modified in the set-up of this section to allow for the exploitation of Industria's monopoly power in the market for manufactures. However, it is to be noted that unlike the first-best discussion of Jones and Kemp, i.e. with $F_{m}^{3}=0$, it is no longer clear that the price faced by Industrian consumers is less than the world price. ${ }^{9}$

The first-best policy for Resourcia is obtained on maximizing $U\left(C_{m}, C_{f}\right)$ subject to

$$
\begin{aligned}
& C_{m}=p_{r} X_{r}-R\left(K_{r}-K\right)+p_{f} C_{f}^{*} \quad \ldots \ldots \\
& \begin{array}{lllll}
C_{f}=X_{f}-C_{f}^{*} & \ldots & \ldots & \ldots & \ldots
\end{array}
\end{aligned}
$$

with $K_{r}, L_{r}$ and $p_{f}$ as the relevant control variables. On letting $q_{f}\left(\equiv U_{f} / U_{m}\right)$ be the relative price of food faced by Resourcian consumers, we can obtain the following necessary conditions.

$$
\begin{gathered}
p_{f}-q=-\frac{C_{f}^{*}}{C_{f p}^{*}} \ldots \\
p_{f} F_{r}^{1}\left(1+\frac{F_{r} F_{m}^{33}}{F_{m}^{3}}-\left(K_{r}-K\right) \frac{F_{m}^{23}}{F_{m}^{3}}\right)=q F_{f}^{1}+\left(q-p_{f}\right) C_{f I^{*}}^{*} \frac{\partial I^{*}}{\partial L_{r}} \\
p_{r} F_{r}^{2}\left(1+\frac{F_{r}}{F_{m}^{3}}\left(F_{m}^{33}-\frac{F_{m}^{32}}{F_{r}^{2}}\right)-\left(K-K_{r}\right)\left(F_{m}^{23}-\frac{F_{m}^{22}}{F_{r}^{2}}\right)\right)= \\
R+\left(q-p_{f}\right) C_{f I *}^{*} \frac{\partial I^{*}}{\partial K_{r}}
\end{gathered}
$$

where Industrian income $I^{*}$ is given by

$$
I^{*}=F_{m}+R\left(K^{*}-K_{u}\right)-p_{r} M \quad \cdots
$$

and obviously responds positively to changes in $L_{r}$ and $K_{r}$

In the case of Resourcia, the optimal policy in the market for food is just as in the traditional theory of trade and investment and, in the absence of inferiority in consumption, calls for Resourcian consumers to face a lower than international price $^{10}$. Equations (5.13) and (5.14) are the corresponding modifications of equations (4.11) and (4.12).

${ }^{9}$ See, for example, Section 3 in Brecher [2].

${ }^{10}$ Indeed equation (5.12) is identical with equation (6) in Brecher [2].

\section{CONCLUDING REMARKS}

We have presented a model of trade and investment which is well suited for answering a variety of questions of both a positive and normative nature. It is, however, worth underscoring that our results rely crucially on the stability result reported in Section 2. To put the point somewhat differently, we could have obtained a variety of results, including paradoxes, based on a variety of assumptions if a stability result did not ensure the positivity of $\Delta$. The importance of stability of equilibrium in narrowing down the range of possible results has, of course, been re-emphasized recently by Neary $[11 ; 12]$.

We have not considered the effects of technical progress concerning which Kemp and Ohyama conclude that it reduces international indebtedness irrespective of the country in which it occurs. We leave it to the reader to check for himself that this result too is not robust with respect to the addition of an additional sector in Resourcia. We also leave it to the reader to derive for himself the effects of factor accumulation and changes in the terms of trade in the case when the prices are exogenously given. There do not seem to be any surprises here beyond what we have discussed in Section 3.

\section{REFERENCES}

1. Bhagwati, J.N., V.K. Ramaswami, and T.N. Srinivasan. "Domestic Distortions, Tariffs and the Theory of Optimum Subsidy: Some Further Results". Journal of Political Economy. Vol. 77. 1969. pp. 1005-1010.

2. Brecher, R.A. "Second-best Policy for International Trade and Investment". Journal of International Economics. Vol. 14. 1983

3. Findlay, R. "Economic Development and the Theory of International Trade". American Economic Review. Vol. 69. 1979. pp. 186-190.

4. Gorman, W.M. "Tricks with Utility Functions". In M. Artis and A. Nobay. (eds.), Essays in Economic Analysis. Cambridge: Cambridge University Press. 1976.

5. Jones, R.W. "International Capital Movements and the Theory of Tariffs and Trade”. Quarterly Journal of Economics. Vol. 81. 1967. pp. 1-38.

6. Jones, R.W. "A Three Factor Model in Theory, Trade and History". In J.N. Bhagwati, R.W. Jones, R.A. Mundell and J. Vanek (eds.), Trade Balance of Payments and Growth. Amsterdam: North-Holland Publishing Co. 1971.

7. Jones, R.W., and F. Dei. "International Trade and Foreign Investment: A Simple Model". Rochester: University of Rochester. 1982. (Discussion Paper No. 82-9)

8. Kemp, M.C. The Pure Theory of International Trade. Englewood Cliffs, N.J.: Prentice-Hall. 1969. 
9. Kemp, M.C., and T. Negishi. "Domestic Distortions, Tariffs and the Theory of the Optimum Subsidy". Journal of Political Economy. Vol. 77. 1969. pp. $1011-1013$.

10. Kemp, M.C., and M. Ohyama. "On the Sharing of Trade Gains by Resourcepoor, and Resource-rich Countries". Journal of International Economics. Vol. 10. 1978. pp. 245-256.

11. Neary, J. Peter. "Dynamic Stability and the Theory of Factor Market Distortions”. American Economic Review. Vol. 68. 1978. pp. 219-234.

12. Neary, J. Peter. "Short-run Capital Specificity and the Pure Theory of International Trade". Economic Journal. Vol. 88. 1978. pp. 59-84.

13. Samuelson, P.A. "Ohlin was Right". Swedish Journal of Economics. Vol. 73. 1971. pp. 365-389. 